\title{
PREDICTIVE IN-VITRO EVALUATION OF FOOD EFFECT ON THE IN-VIVO PERFORMANCE OF CHLORPROPAMIDE TAB LET
}

\author{
*Awofisayo SO ${ }^{1}$, Ukpong Emmanuel Effiong ${ }^{1}$, Umoren FJ ${ }^{2}$, Uwanta EJ ${ }^{3}$, Nnamdi JA ${ }^{4}$ \\ ${ }^{1}$ Department of Clinical Pharmacy and Biopharmacy, Faculty of Pharmacy, Box 4257, University of Uyo, Rest Office, 520003, Uyo,
}

Nigeria

${ }^{2}$ Department of Chemistry, Michael Okpara University of Agriculture, Umudike, Nigeria

${ }^{3}$ Department of Chemistry, Akwa Ibom State University, Ikot Akpaden, Nigeria

${ }^{4}$ Department of Pharmaceutics and Pharmaceutical Technology, Faculty of Pharmacy, University of Benin, Nigeria

Corresponding Author's Email: jdjide@yahoo.com,jdideresearch@yahoo.com,Tel: 2348037947338

Received 27 May 2012; Review Completed 25 June 2012; Accepted 11 July 2012, Available online 15 July 2012

\begin{abstract}
ABS TRACT
This study compared the disintegration time and dissolution profile of the hypoglyceamic drug product, chlorpropamide marketed in Nigeria as Chlorbinese in simulated gastric fluid (SGF), simulated intestinal fluid SIF, food modified gastric fluid (FMSGF) and intestinal fluid (FMSIF) as a measure of the effect of dosing condition on in-vivo drug performance. Various quality control parameters including weight uniformity, tablet hardness, disintegration, friability and assay were assessed prior the dissolution profile determination. Food containing media were prepared by blending $1.3 \mathrm{ml}$ full cream fat containing milk and $25 \mathrm{mg}$ of soluble starch was added to $500 \mathrm{ml}$ and $300 \mathrm{ml}$ of SGF and SIF to make FMSGF and FMSIF respectively. The in-vivo performance of the drug at the dosing conditions was also determined using 24 healthy volunteers with post dosing administration of drug and blood sampling. The titrimetric and spectrophotometric assays gave $99.37 \%$ and $104.12 \%$ of chlorpropamide content respectively $(\mathrm{P}<0.05)$. No significant differences were observed between the disintegration time for FMSGF, SGF, SIF and FMSIF being $(5 \mathrm{~s}, 4 \mathrm{~s}, 4 \mathrm{~s}$ and $6 \mathrm{~s})$ respectively at $\mathrm{P}<0.05$. There was no significant difference in the percentage drug release in FMSIF compared with SIF (40\% v 35\%) similarly there was no difference in the release rate for media simulating dosing conditions in the stomach revealing (28\% v $28 \%)$ release at $\mathrm{P}<0.05$. There was no significant difference in the change in blood glucose level in the volunteers with respect to the dosing conditions $\mathrm{P}<0.05$.

Dosing conditions did not affect the drug release and blood glucose reduction of chlorpropamide tablet.

Keywords: Chlorpropamide, Food effect, Simulated media, Drug release .Glucose level
\end{abstract}

\section{INTRODUCTION}

Drug interaction with food and beverages are known to occur exemplified by the well known interaction between monoamine oxidase inhibitor and tyramine containing food ${ }^{1}$. Grapefruit juice caused the most clinically relevant of these interactions as typified in concomitant administration of simvastatin with grape juice leading to increased risk of statin-induced adverse effects such as myopathy ${ }^{2}$.

The dissolution and absorption of certain drugs such as tetracyclines, flouroquinolones have been reported to be markedly reduced if administered with milk and other dairy products. The absorption of aspirin and other salicylates have also been shown to be delayed by the presence of food while ketoconazole and itraconazole have been increased ${ }^{3-5}$.

Chlorpropamide is a sulphonylurea and a long acting hypoglyceamic agent widely prescribed for patients with Type II diabetes mellitus. In non insulin dependent diabetes mellitus (NIDDM), diet is usually restricted as a supportive in the control of blood sugar. The concomitant administration of food or drink with the oral hypoglyceamic agent may affect the rate and extent of dissolution and consequently the absorption of the drug ${ }^{6}$. Linking drug doses to daily routines such as meal times can improve patient's compliance; however, the possible alteration of the pharmacokinetics of the drug is an issue worthy of note. Majority of reported events of therapeutic failure in the world may be due to factors that include the presence of certain food substances that can reduce the dissolution and absorption of drugs in the gastrointestinal $\operatorname{tract}^{7,8}$.

Chlorpropamide is indicated as an adjunct to diet and exerc ise to improve glyceamic control in adults. It lowers the blood glucose acutely by stimulating the release of insulin from the pancreas thereby exerting hypoglyceamic effect in normal subjects in about an hour and the maximum concentration in systemic circulation is achieved in 2-3 hours post dose. Chlorpropamide binds to plasma protein and loss of blood sugar control has been reported following concomitant administration of certain drugs such as the non steroidal anti-inflammatory drugs (NSA ID) and sulphonamides. There has been no documentary evidence of the pattern of drug level of chlorpropamide when taken with certain food eaten in the tropics ${ }^{9}$. The presence or absence of food (state of fill of the stomach) determines the rate of emptying of the gastric content into the duodenum. Factors that tend to delay gastric emptying include fat content of meal, temperature and nature of fluid taken i.e. beverages ${ }^{10-12}$. 
Food effects are usually not predictable. Generally, the presence of food in the gastric lumen stimulates the flow of bile acids which act as surfactants involved in the solubilization of fats and lipophilic drugs ${ }^{6-9}$.

The study had the objective of establishing whether there are differences in the dissolution pattern of chlorpropamide tablet in SGF, FMSGF, SIF and FMSIF. The study also evaluates the dosing effect on the the performance of chlorpropamide.

\section{MATERIALS AND METHOD}

\section{Materials}

Ethanol, methanol and acetone were products of Sigma Aldrich Chemicals Germany; acetic acid, sodium hydroxide, hydrochloric acid, sodium chloride, sodium dihydrogen phosphate and potassium phosphate products of Kernel Chemicals UK.

\section{Commercial Tablet}

A pack of 100 by $250 \mathrm{mg}$ of chlorpropamide was purchased for the study. Details of tablet description are outlined in Fig. 1.

\section{Prepared Reagents}

\section{Study Media}

\section{Simulated Intestinal Fluid}

$40 \mathrm{~g}$ of sodium hydroxide and $34 \mathrm{~g}$ of monobasic potassium phosphate were added to $2 \mathrm{~L}$ of distilled water and the volume made up to $5 \mathrm{~L}$ mark in a volumetric flask ${ }^{13,14}$. The resulting $\mathrm{pH}$ was 7.32 .

\section{Simulated gastric fluid}

$43 \mathrm{ml}$ of concentrated hydrochloric acid was added to $2 \mathrm{~L}$ of distilled water in a volumetric flask. This was followed with $500 \mathrm{ml}$ of $20 \%$ sodium chloride solution and the final volume made up to $5 \mathrm{~L}^{13,14}$ mark. The resulting $\mathrm{pH}$ was 1.13

\section{Food modified SGF and SIF}

Food modified SGF and SIF was prepared by adding $100 \mathrm{ml}$ of peak milk and $25 \mathrm{mg}$ of soluble starch with $500 \mathrm{ml}$ of SGF or $300 \mathrm{ml}$ of SIF to get food modified SGF and SIF respectively ${ }^{15}$.

\section{Calibration curve}

Four tablets of chlorpropamide $250 \mathrm{mg}$ were crushed into fine powder and extracted in $40 \mathrm{ml}$ acetone. The drug in acetone was filtered and the filtrate was left in a crucible and allowed to evaporate at room temperature. $16 \mathrm{mg}$ of the recovered drug was dis solved in $40 \mathrm{ml}$ of methanol and $0.1 \mathrm{~N}$ hydrochloric acid used to make up to $50 \mathrm{ml}$ to obtain the stock solution. $5 \mathrm{ml}$ of the prepared stock was diluted to $100 \mathrm{ml}$ with $0.01 \mathrm{M}$ hydrochloric acid and this was further diluted to give concentrations of 1.6, 3.2, 4.8, 6.4, 8.0, 9.6, $11.2,12.8$ and $14.4 \mu \mathrm{g} / \mathrm{ml}$. The absorbance of the various concentrations was read off from the UV spectrophotometer at $232 \mathrm{~nm}$. The result was comapred with the titrimetric procedure involving the quantitative determination of the amount of chlorpropamide released from the tablet by the reaction of the excess base in solution with perchloric acid.

\section{Drug administration and ethical protocols}

The study protocol and the informed consent forms were approved by the Ethical Committee of the University of Uyo Health Services, Uyo, Nigeria. The whole study which meets the requirements of the declarations of Helsinki was conducted in accordance with the Current Good Clinical Practice (GCP), International Conference Harmonization (ICH) as well as Good Laboratory Practice (GLP) Guide lines ${ }^{16,17}$.

Twenty four young adult healthy volunteers, non smokers, aged Mean \pm SD $(27.4 \pm 5.6)$ years and body weight Mean $\pm \mathrm{SD} 72.5 \pm 6.3 \mathrm{Kg}$ were recruited into the study. The volunteers were not on concomitant medications and they were free from any significant cardiac, hepatic, renal, pulmonary, gastrointestinal, neurological or hematological disease as reported from a physical examination and laboratory tests along with medical history probe conducted by a qualified physician four weeks prior the commencement of the study. The volunteers were given a written informed consent write-up which explained the nature of the study. All the volunteers were willing to participate in the study and were requested to abstain from drug and alcohol for three days prior the study. They were also requested to fast for at least 10 hours overnight before drug administration. The volunteers were randomly selected and grouped into two consisting of 6 males and 6 females per group. The first group was given $250 \mathrm{mg}$ chlorpropamide tablet before food. The blood sugar levels were read off before the dosing and exactly 3 hours post dose. The second group was similarly treated but dosed after ingestion of two sliced bread with $35 \mathrm{cl}$ of milk made with two heaped teaspoonful Peak powdered milk. The volunteers were not restrained from drinking water as desired during the study. The study had an open randomized crossover design with a 14-day washout period between the doses.

\section{Statistical anal ysis}

Statistical significance in the values of disintegration and dissolution outcome in the different media were evaluated through one sample hypothesis and one tail at $\alpha=0.05$. Significance difference in the mean blood glucose reduction within and among the group was evaluated using one way ANOVA and chi square.

\section{RESULT}

The details of the drug used in the study are laid out in Table 1 . The physicochemical parameters of the drug are expressed in Table 2. The dissolution and disintegration indices of chlorpro mazine hydrochloride tablet employed in the various simulate media are presented in Table 3. The dissolution profile of the drug in the various media is given in Fig 1. The calib ration curve parameters are expressed in the equation below.

$$
\mathrm{Y}=2.34 \mathrm{x}+0.0021 ; \mathrm{R}=0.969
$$

The resulting $\mathrm{pH}$ of the FMSGF and FMSIF are 2.7 and 7.9 respectively. The outcome of the blood sugar measure ments are presented in Table 4. 
Table 1: The properties of used drugs

\begin{tabular}{|l|l|}
\hline Brand name & Chlorpropamide \\
\hline Tablet Strength & $250 \mathrm{mg}$ \\
\hline Manufacturer & Neimeth Pharmaceuticals \\
\hline Country of manufacture & Nigeria \\
\hline Registration nu mber & $04-7517$ \\
\hline Batch number & 00117003 \\
\hline Manufacturing date & $08-2010$ \\
\hline Expiry date & $08-2013$ \\
\hline
\end{tabular}

Table 2: Disintegration time and Dis solution indices of chlorpropamide tablet in the various media

\begin{tabular}{|l|l|l|l|l|l|l|l|}
\hline \multicolumn{4}{|c|}{ Disintegration time and dissolution $\mathrm{C}_{45}$ in the media } \\
\hline \multicolumn{4}{|c|}{ Disintegration time (min) } & \multicolumn{4}{c|}{$\mathrm{C}_{45}$ values (\%) from dissolution profile } \\
\hline SGF & SIF & FMSGF & FMSIF & SGF & SIF & FMSGF & FMSIF \\
\hline $4.0 \pm 0.5$ & $4.0 \pm 0.6$ & $5.0 \pm 0.5$ & $6.0 \pm 0.4$ & 28.0 & 35.0 & 28.0 & 40.0 \\
\hline
\end{tabular}

Table 3: The analys is of physicochemical properties of chlorpropamide tablet

\begin{tabular}{|l|l|l|l|l|}
\hline \multicolumn{3}{|c|}{ Physicochemical properties of chlorpropamide } \\
\hline Friability (\%) & Crushing Strength $\left(\mathrm{Kg} / \mathrm{cm}^{2}\right)$ & Weight Uniformity $(\mathrm{mg})$ & \multicolumn{2}{|c|}{ Chemical content determination (\% w/w) } \\
\cline { 4 - 5 } & & & Back titration & UV spectrophotometer \\
\hline $0.079 \pm 0.001$ & $2.1 \pm 0.6$ & $317.29 \pm 0.67$ & $99.37 \pm 0.43$ & $104.12 \pm 0.67$ \\
\hline
\end{tabular}

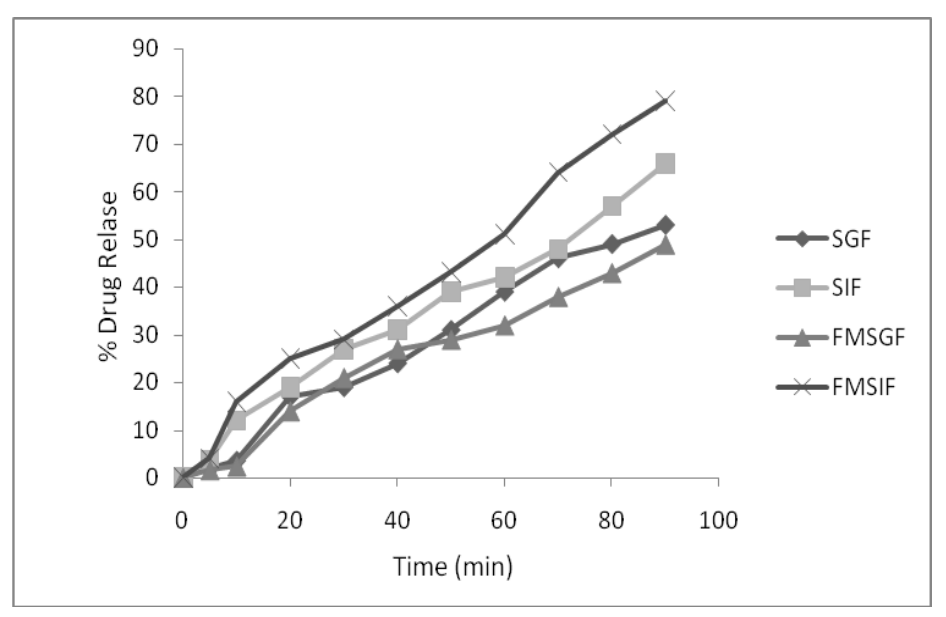

Fig 1: The dis solution profile of chlorpropamide in the four dis solution media

Table 4: The statistical analys is of the blood sugar level outcome of the groups of volunteers $(n=12)$ on ad min is tration of chlorpropamide at different dosing conditions

\begin{tabular}{|l|l|l|l|l|}
\hline \multicolumn{7}{|c|}{ The statistical indices of the groups } \\
\hline Groups & $\sum \Delta \mathrm{BS}$ & $\sum \Delta \mathrm{BS} / \mathrm{n}$ & $\mathrm{SD}$ & $\mathrm{P}$ \\
\hline Group A (+F) & 170 & 14.2 & 8.6 & 0.835 \\
\hline Group A (-F) & 145 & 12.1 & 9.8 & 0.409 \\
\hline Group B (+F) & 185 & 15.4 & 6.8 & 0.545 \\
\hline Group B (-F) & 210 & 17.5 & 9.5 & 0.633 \\
\hline
\end{tabular}

$-F=$ with food $;+F=$ without food, $\Sigma \Delta B S=$ Change in Blood sugar level $(\mathrm{mg} / \mathrm{dl})$

$\alpha=0.05$ and significance at $P<0.05$

\section{DISCUSS ION}

The quality control parameters of the studied drug complied with the official specifications in BP 1973, this gives the confidence of the choice of brand of drug used for the study ${ }^{18}$. UV spectrophotometric determination and titrimetric methods were employed for the chemical content determination in this work as these are the commonly accessible means of quantitative analysis in

developing countries. The methods were validated and the difference in the assay values was found to be statistically insignificant. Routine determinations like this may be performed using the available instrumentation method such as UV spectrophotometry. The disintegration time and dissolution profile of chlorpropamide respectively in SIF $(4.0 \mathrm{~s}, 35 \%)$ and SGF $(3.5 \mathrm{~s}, 28 \%)$ also gives the impression of better release pattern despite the delay in 
the disintegration time of the dosage form when compared to the fed state simulated condition FMSIF (6.0s, 40\%) and FMSGF (5.0s, 28\%). Chlorpropamide a basic compound disintegrates to more or less the same extent in SIF $(\mathrm{pH}$ 7.32) and SGF (pH 1.13). The wide difference in $\mathrm{pH}$ did not affect the kinetics of disintegration contrary to expectation. This may be due to the formulation characteristics of the drug i.e. other brands may exhibit difference in disintegration profile. Drugs which occur as salt may have common ion effect influencing the dissolution profile. For food to significantly affect the dissolution of the drug it is expected that the $T_{70}$ for the food modified med ia be higher than 45 min ${ }^{19}$.The SIF and SGF revealed unsatisfactory $\mathrm{T}_{70}$ values just as the FMSGF and FMSIF hence the values of the food simulated media being found to be statistically not different from the fasted simulated conditions simply indicates that food did not influence the drug disposition. The food modified media

\section{REFERENCES}

1. Walker $\mathrm{R}$ and Whifflesea C. Clinical Pharmacy and Therapeutics. 4th Ed. Elsevier Ltd. 2008; 41-46

2. Amcet B and Winfraud RA. Drug Interaction with grapefruit juice. Clinical Pharmacokinetics. 1997; 33:103-121

3. Aulton ME. Pharmaceutics:The Science of dosage form design. Harcourt Brace and Company Ltd, New York, USA1998; 247-248, 302-312 and 662-667

4. Bakare MT, Mustapha A and Abolu AJ. Effect of Nigerian meals on the pharmacokinetics of chlorpropamide in Type II diabetic patient. European Journal of Pharmaceutics 2008; 33:31-35.

5. Feldman EB. How grapefruit juice potentiates drug bioavailability. Nutritional Review. 55: 398-400

6. Kirk JK. Significant drug-nutrient interactions. American Family Physician.1995; 51(5): 1175-1182.

7. Lamy PP. Effect of diet and nutrition on drug therapy. Journal of American Geriatric Society. 1982; 30: 599-611

8. Thomas JA. Drug-nutrient interactions. Nutritional Review. 1995, 53. 271-282.

9. Antal EJ, Gillesspic WR, Philip JP, Albert KS. The effect of food on the bioavailability and pharmacodynamics of chlorpropamide in diabetic patients. European Journal of Clinical Pharmacology, 1974;7(1):47-49

10. Feldman EB. How grapefruit juice potentiates drug bioavailability. Nutritional Review. 1997; 55:398-400.

11. Gillian MS. Drug interactions with oral hypoglyceamic drugs. Pharmacokinetics, Australian Prescriber. 2001;24: 83-85. were designed to simulate the food composition possibly available after a typical African diet ${ }^{20}$. The presence of dissolved solutes is typified in the presence of the food materials added to the media which are expected to reduce the solvent power and invariably the release rate of the drug from the drug product ${ }^{9}$. The one sample statistics gave the various means with mean difference of 2.45 and a hypothesized mean difference of 0 . The confidence limit at both one tail and two tail consideration produced $\mathrm{F}$ values indicating that no statistical difference in the change in blood sugar levels of the group with respect to the dosing conditions. The single factor ANOVA revealed no difference in the mean blood sugar reduction for the

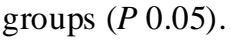

\section{CONCLUS ION}

The dosing conditions did not significantly affect the disintegration and dissolution profile of chlorpropamide.

12. Pronsky Z. Powers and Moore's food medication interactions. Ebsco Publishers, Pottstown. 2007:p 60.

13. Awofisayo SO, Uwanta EJ. The dissolution profile of six brands of ketoconazole tablets in dissolution media simulating the proximal human gastrointestinal tract. Journal of Pharmacy Research. 2011; 4(7) 1962-1964

14. Dressman JB, Vertzoni M, Goumas K, Reppas C. Estimating drug solubility in the gastrointestinal tract. Advanced Drug Delivery Review. 2007; 59(7): 591-602.

15. Guideline for good clinical practice E6( R1): International conference on harmonisation (ICH) of technical requirements for registration of pharmaceuticals for human use; 1996.

16. Handbook: good laboratory practice (GLP): quality practices for regu lated non-clinical research and development. 2nd ed: World Health Organization; 2009.

17. Wagner D, Spalon-Langguth H, Theray A abnd Languth $P$. Intestinal drug efflux, formation and food effects. Adv Drug Delivery Review. 2001, 50 (Suppl) 513-531.

18. The British Pharmacopoeia. Her Majesty's Stationery Offfice Press, London. 2004.

19. Alderborn G. Tablet and compaction in Aulton M. E. (Ed) Pharmaceutics. The Science of dosage form design. $2^{\text {nd }}$ ed. Elsevier science Limited. 2002: 397-440.

20. Mozay ani A, Ray mond LP. Handbook of Drug InteractionsA clinical and forensic guide. Human Press Ltd. Totowa, New Jersey, USA. 2004. 